\title{
O enfermeiro docente no ensino superior: atuação e formação profissional
}

\section{The nurse teacher in higher education: performance and professional training}

\section{La Facultad de enfermería en la educación superior: formación y la práctica}

\author{
João Paulo Soares Fonseca ${ }^{1}$ \\ Carla Helena Fernandes ${ }^{1}$
}

DOI: http://dx.doi.org/10.20435/serie-estudos.v22i45.1027

\begin{abstract}
Resumo: A pesquisa foi desenvolvida junto a enfermeiros que atuam como docentes, em instituições de ensino superior localizadas no Sul de Minas Gerais. Objetivou investigar a formação desses docentes (específica e pedagógica) estabelecendo possíveis relações com a atuação docente. A investigação se constituiu de questionários, enviados para todos os docentes que atuam na região, tendo respondido quarenta e um docentes. Constatou-se que a entrada na carreira docente se deu, em muitos casos, simultânea ao início da atuação na enfermagem; muitos docentes têm formação pedagógica e a consideram importante para a docência; os participantes da pesquisa também afirmaram que a docência tem se constituído na/da relação com a experiência profissional em contextos de Saúde; os profissionais disseram ainda da história e da trajetória, de reflexões sobre a formação e a atuação profissional.
\end{abstract}

Palavras-chave: docência; enfermagem; formação de professores.

Abstract: The research was developed with nurses who work as teachers in higher education institutions located in the south of Minas Gerais. It aimed to investigate the education of these teachers (specific and pedagogical) establishing possible relationships with the teaching performance. The investigation consisted of questionnaires, sent to all teachers who work in the region. Fortyone teachers answered the questionnaires. It was verified that the entrance in the teaching career occurred, in many cases, simultaneously to the beginning of the nursing action; Many teachers have pedagogical training and consider it important for teaching; The participants of the research also said that teaching has been constituted in the relation with the professional experience in contexts of Health; The professionals also talked about the history and the trajectory, the reflections on education and the professional performance.

Key words: teaching; nursing; teacher training.

Resumen: La encuesta fue desarrollada con enfermeras que trabajan como profesores en instituciones de educación superior ubicado en el sur de Minas Gerais. Pretende investigar la formación de estos

${ }^{1}$ Universidade do Vale do Sapucaí (UNIVAS), Pouso Alegre, Minas Gerais, Brasil. 
profesores (pedagógico y) establecer posibles relaciones con el profesor temporario. La investigación se constituyó de cuestionarios enviados a todos los maestros que trabajan en la región, habiendo contestado 41 profesores. Se observó que la entrada en la carrera docente llevó a cabo, en muchos casos, simultáneamente al inicio de la actuación en enfermería; muchos profesores tienen formación pedagógica y que es importante a la enseñanza; encuestados afirmó también que la enseñanza se ha constituido en la relación con la experiencia profesional en contextos de salud; los profesionales, dijo la historia y trayectoria, reflexiones sobre la formación y desempeño profesional.

Palabras clave: enseñanza; de enfermería; formación de los docentes.

\section{INTRODUÇÃO}

O campo da enfermagem vem sofrendo modificações nas diferentes formas de se praticar essa profissão. Uma boa parte de profissionais da enfermagem vem assumindo as salas de aula, um espaço a priori usado para o ensino e habilitação do enfermeiro. A docência torna-se, então, uma oportunidade de atuação frequente dentre as diversas possibilidades que a enfermagem proporciona. Diante dessa realidade, profissionais da enfermagem, cuja formação inicial está voltada à área da assistência à saúde, têm assumido a docência em cursos de ensino técnico e superior.

A inserção de enfermeiros bacharéis na sala de aula pode ser analisada por algumas vertentes. É preciso considerar, em muitos casos, a ausência da formação pedagógica e, ao mesmo tempo, cabe refletir sobre o lugar que o exercício profissional em Enfermagem tem na construção dos saberes e práticas docentes.

Este estudo trata do recorte de uma pesquisa realizada com profissionais que atuam em instituições de Ensino Superior localizadas no Sul de Minas Gerais, que teve como encaminhamento estudo exploratório-descritivo, organizado em duas fases. Na primeira, foi enviado questionário elaborado pelos pesquisadores para profissionais que atuam em instituições da região, tendo respondido quarenta e um enfermeiros. Na segunda fase, foram realizadas com um grupo menor de docentes entrevistas semiestruturadas, cujo objetivo foi investigar a formação do enfermeiro que assume a docência no Ensino Superior, buscando levantar dados acerca da formação (específica e pedagógica) desses profissionais, estabelecendo possíveis relações entre essa formação e a atuação docente. A investigação tem como direcionamento as seguintes questões: Como se constituem os conhecimentos acerca da docência de enfermeiros que assumem a sala de aula no ensino superior? Há relação entre conhecimentos do exercício profissional e a docência? Qual o papel da formação pedagógica? Com esse encaminhamento, esta pesquisa se propôs a 
olhar para o enfermeiro a fim de conhecer seu percurso bem como suas práticas, que o fazem professor.

\section{O ENFERMEIRO DOCENTE: FORMAÇÃO E ATUAÇÃO PROFISSIONAL}

Segundo Masetto (2012), um grande problema que enfrentamos atualmente com relação aos professores universitários são as mudanças sociais e a falta de formação pedagógica, e muitos deles desenvolvem uma didática, ao longo dos anos, fazendo da sala de aula "seu laboratório". Para Behrens (2012), o simples transmitir do conteúdo já não é suficiente; a reprodução de um molde- "escute, leia, decore e repita" - já não cabe nas mudanças necessárias ao Ensino Superior.

Vivemos em uma sociedade em que tudo é informação, portanto torna-se imprescindível que o docente acompanhe as transformações sociais, não na velocidade das máquinas, pois isso não seria possível, mas abandonando formas sedimentadas por um passado significativo e importante que serviu de base para a construção e formação, mas que já não Ihe serve e até mesmo atrapalha a evolução do profissional e da própria instituição (CICILLINI, 2010).

$\mathrm{Na}$ enfermagem, por ser uma atividade que tem como atuação primeira a assistência à saúde, os profissionais se dirigem ao trabalho em hospitais e clínicas, públicas e particulares, além de centros de saúde direcionados ao atendimento das famílias por meio de ações e programas. A formação, atualmente, se dá por meio do Bacharelado. Contudo muitos profissionais optam pela pesquisa e pela docência, exercendo-a em cursos específicos (de nível médio e no Ensino Superior) e afins. Esse fato trouxe para a profissão o debate da formação para a docência, o que não tem se dado de forma isolada na discussão da própria profissão.

A formação do enfermeiro atuando como docente deve ser consolidada com base no domínio de conhecimentos científicos e na atuação investigativa no processo de ensinar e aprender, recriando situações de aprendizagem por investigação do conhecimento de forma coletiva, com o propósito de valorizar a avaliação diagnóstica dentro do universo cognitivo e cultural dos acadêmicos como processos interativos (SOUZA, 2013; RODRIGUES; MENDES SOBRINHO, 2007).

Tardif (2000) repensa a formação dos professores levando em conta os saberes dos docentes e as realidades específicas do trabalho cotidiano, reconhecendo o professor como um profissional produtor de saberes. Entende o saber docente como aquele formado pela associação, mais ou menos coerente, de saberes oriundos da: formação profissional, transmitidos pelas instituições de formação de professores; 
disciplinares, que correspondem aos diversos campos do conhecimento; curriculares, das instituições escolares, compreendem os discursos, objetivos, conteúdos e métodos que os professores devem aprender a aplicar; e experiências, baseados no seu trabalho cotidiano, brotam da experiência e são por ele validados. Ainda considera os saberes experienciais como núcleo vital do saber docente.

\section{FORMAÇÃO E DOCÊNCIA: DESCRIÇÃO, INTERPRETAÇÃO E DISCUSSÃO DOS RESULTADOS}

Neste tópico, são apresentados os resultados produzidos a partir do questionário elaborado e enviado aos enfermeiros, via Formulário Google Docs. O questionário foi construído pelo pesquisador com base nos objetivos da pesquisa, composto por questões abertas e uma questão fechada, que se dirigem às temáticas da atuação e da formação profissional. Busca, também, compreender a concepção do profissional acerca da sua atuação e, em especial, sobre a relação entre ser professor e enfermeiro.

Dos 41 sujeitos respondentes, 33 são do sexo feminino e oito do sexo masculino. Em relação à idade desses profissionais, 7,3\% estão na faixa de 20 a 30 anos; 36,6\%, entre 31 a 40 anos; 26,8\%, entre 41 a 50 anos; e 29,3\%, acima de 51 anos. Já em relação à formação acadêmica, $22 \%$ dos sujeitos têm especialização, 48,8\% possuem mestrado e $29,2 \%$, doutorado, o que sugere, por um lado, a busca pela continuidade da formação e aprimoramento profissional e, por outro, uma possível resposta às solicitações do MEC para o Ensino Superior. Outro ponto a se destacar no questionário é referente à segunda graduação, além da Enfermagem, sendo observados os seguintes cursos: Ciências Biológicas, Farmácia, Biologia, Pedagogia e Normal Superior.

Ainda, em relação à formação profissional, os resultados apresentados na Tabela 1 referem-se ao ano de conclusão da graduação.

Tabela 1 - Ano de conclusão da graduação

\begin{tabular}{|c|c|c|c|}
\hline Conclusão graduação & Anos & No sujeito & \% \\
\hline 1975 a 1985 & 30 a 40 & 10 & $24 \%$ \\
\hline 1986 a 1996 & 19 a 29 & 13 & $32 \%$ \\
\hline 1997 a 2007 & 08 a 18 & 15 & $37 \%$ \\
\hline 2008 a 2015 & Até 07 & 03 & $7 \%$ \\
\hline
\end{tabular}

Fonte: Questionário aplicado pelo autor (2015). 
Os dados apresentados na Tabela 1 indicam que 24\% dos docentes que responderam ao questionário (dez professores) formaram-se entre os anos de 1975 e 1985, completando tempo de formados de 30 a 40 anos; 32\% (treze professores) formaram-se entre os anos de 1986 e 1996, com 19 a 29 anos de formados; 37\% dos docentes (quinze professores) formaram-se entre os anos de 1997 e 2007, completando o tempo de formados de 08 a 18 anos; e 7\% (três professores) formaram-se entre 2008 e 2015, tendo até 7 anos de graduados. Observa-se que os profissionais com mais tempo de formação concluíram a graduação nos anos de 1977 (um sujeito) e 1979 (quatro sujeitos); os profissionais mais recentes da pesquisa formaram-se em 2010 (um sujeito) e 2011 (dois sujeitos).

Quanto ao tempo de atuação como enfermeiro, a Tabela 2, apresentada na sequência, indica:

Tabela 2 - Atuação profissional como enfermeiro

\begin{tabular}{|c|c|c|}
\hline Anos & No sujeito & $\%$ \\
\hline 30 a 40 & 07 & $17 \%$ \\
\hline 19 a 29 & 10 & $24,5 \%$ \\
\hline 08 a 18 & 14 & $34 \%$ \\
\hline Até 07 & 05 & $12 \%$ \\
\hline Nunca & 02 & $5 \%$ \\
\hline Não respondeu & 01 & $2,5 \%$ \\
\hline Somente como supervisores de estágio & 02 & $5 \%$ \\
\hline Total & 41 & $100 \%$ \\
\hline
\end{tabular}

Fonte: Questionário aplicado pelo autor (2015).

Os dados apresentados na Tabela 2 indicam que 17\% dos docentes pesquisados (sete) estão na assistência como enfermeiro de 30 a 40 anos, 24,5\% (dez) atuam na área entre 19 a 29 anos, 34\% (catorze) atuam há cerca de 08 a 18 anos, 12\% (cinco) responderam que exercem a função há 7 anos ou menos. Ainda $5 \%$ (dois) dos enfermeiros afirmaram que nunca atuaram na área da assistência, 2,5\% (um) não responderam a esse item do questionário e $5 \%$ (dois) responderam que atuaram somente como supervisores de estágio.

Os resultados apresentados na Tabela 3 se referem ao tempo de atuação como docentes. 
Tabela 3 - Atuação profissional como docente

\begin{tabular}{|c|c|c|}
\hline Anos & No sujeito & $\%$ \\
\hline 30 a 40 & 03 & $7 \%$ \\
\hline 19 a 29 & 12 & $29,5 \%$ \\
\hline 0 a 18 & 19 & $46,5 \%$ \\
\hline Até 07 & 07 & $17 \%$ \\
\hline & 41 & $100 \%$ \\
\hline
\end{tabular}

Fonte: Questionário aplicado pelo autor (2015).

Os dados apresentados na Tabela 3 indicam que 7\% (três professores respondentes) atuam na docência há cerca de 30 a 40 anos, 29,5\% (doze professores) atuam de 19 a 29 anos, 46,5\% (dezenove professores) trabalham na área de 08 a 18 anos e 17\% (sete professores) há sete anos ou menos.

Os resultados apresentados na Tabela 4 referem-se ao tempo de atuação como docentes no Ensino Superior.

Tabela 4 - Atuação como docente Ensino Superior

\begin{tabular}{|c|c|c|}
\hline Anos & No sujeito & \% \\
\hline 30 a 40 & 02 & $4,9 \%$ \\
\hline 19 a 29 & 12 & $29,2 \%$ \\
\hline 08 a 18 & 17 & $41,5 \%$ \\
\hline Até 07 & 10 & $24,4 \%$ \\
\hline
\end{tabular}

Fonte: Questionário aplicado pelo autor (2015).

Os dados apresentados na Tabela 4 indicam que 4,9\% (dois professores respondentes) atuam na docência de 30 a 40 anos, 29,2\% (doze professores) já lecionam entre 19 a 29 anos, 41,5\% (dezessete professores) exercem a profissão de 08 a 18 anos e $24,4 \%$ (dez professores) estão atuando há 7 anos ou menos.

Dos 41 respondentes, 68,3\% já atuaram em curso de nível médio (técnico em enfermagem) e 31,7\%, não, indicando, provavelmente, que iniciaram suas atividades como professores de nível superior (na graduação em Enfermagem).

Perguntou-se também a esses enfermeiros que assumiram a docência se possuíam algum tipo de formação pedagógica. Dos respondentes, 63,4\% afirmaram que sim, e 36,6\%, disseram que não. Pontua-se que a formação pedagógica permite ao docente olhar para sua própria prática pedagógica, propiciando, assim, sua reestruturação (JUNGES; BEHRENS, 2015). Ainda, segundo as autoras, a docência 
universitária exige que o professor vá além da sua formação específica ao buscar o conhecimento em fundamentos pedagógicos.

Porém, não se pode considerar este como o único conhecimento necessário à docência, no que também contribui a própria experiência profissional. Além disso, a formação pedagógica não pode ser engessada em conhecimentos dissociados da realidade. Segundo Tardif (2000), o saber profissional se constitui pela construção cotidiana e pela reflexão sobre seu trabalho diário; é um "saber plural, formado de diversos saberes provenientes das instituições de formação, da formação profissional, dos currículos e da prática cotidiana" (TARDIF, 2000, p. 54).

Além disso, conforme Rodrigues e Mendes Sobrinho (2007), para se tornar um professor, é necessário que esse profissional tenha vivência da prática na área específica em que ele leciona. Ainda, segundo os autores, a formação desse enfermeiro e docente requer rever continuamente a prática desenvolvida, considerando-o assim como um pesquisador. Para Nóvoa (1999, p. 23), o aprender permanente em sua rotina é essencial para a formação. $O$ docente se constitui pela construção cotidiana e pela reflexão sobre o trabalho diário.

O Gráfico 1 apresenta o motivo da escolha pela docência, sendo que para 7,5\% (três sujeitos) a razão está relacionada ao financeiro, 67,5\% (vinte e sete sujeitos) expressam o interesse pela área, $12,5 \%$ (cinco sujeitos) se referem à diversificação de atividades e para outros $12,5 \%$ (cinco sujeitos) são diversos motivos/escolhas pela docência.

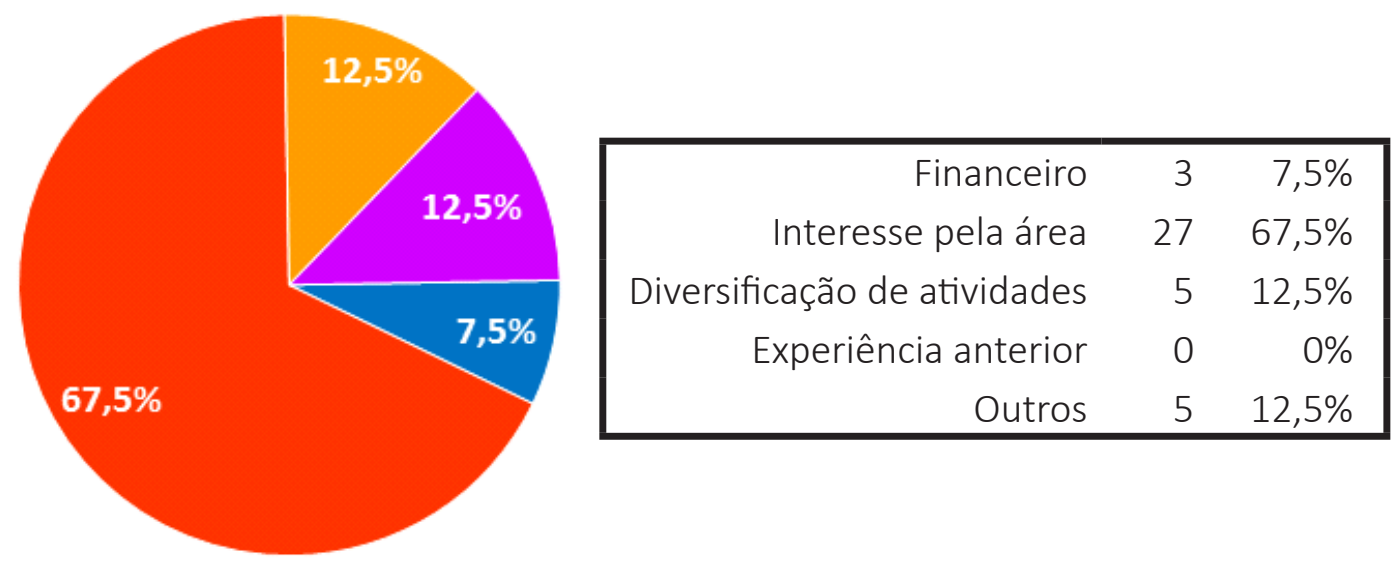

Gráfico 1 - Motivo da escolha pela docência Fonte: Questionário aplicado pelo autor (2015). 
Em relação ao motivo da escolha pela docência no Ensino Superior (Gráfico 2), $10 \%$ (quatro sujeitos) dos respondentes indicaram que está relacionado ao financeiro; 65\% (vinte e seis), relacionado ao interesse nesse nível de ensino; 15\% (seis sujeitos) buscam a pesquisa; e 10\% (quatro sujeitos) afirmaram serem outros os motivos da escolha.

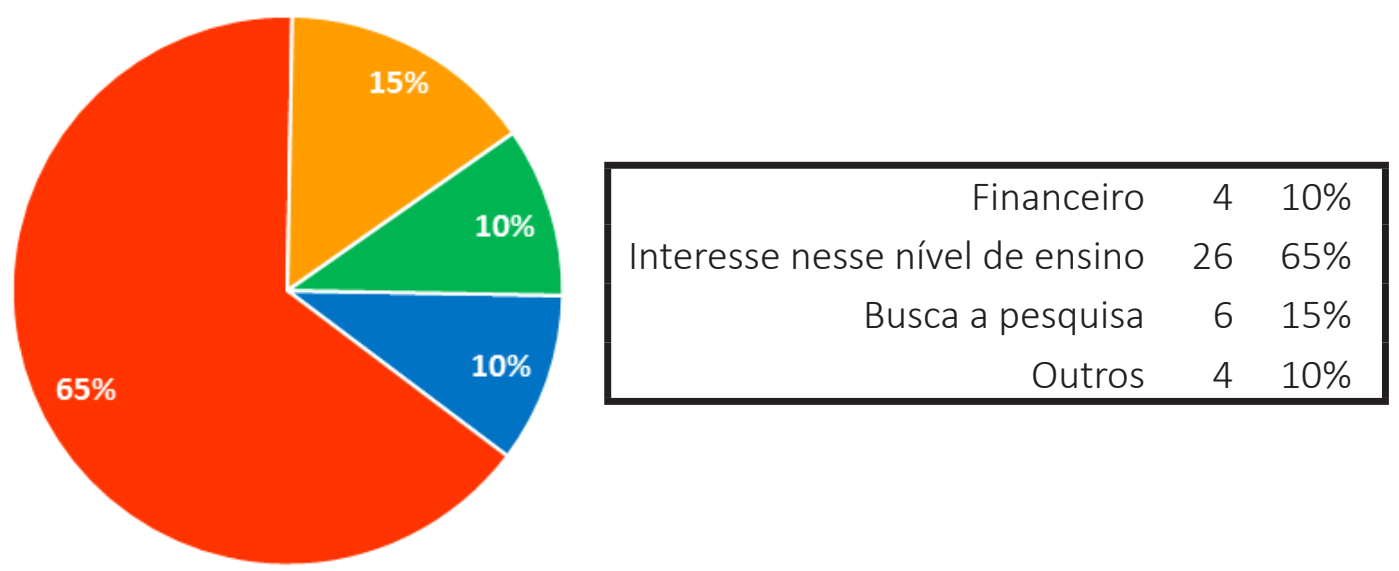

Gráfico 2 - Motivo da escolha pela docência no Ensino Superior Fonte: Questionário aplicado pelo autor (2015).

Para Masetto (2012), a docência no Ensino Superior requer uma atenção especial, pois o docente tem papel fundamental no processo de ensino-aprendizagem. Esse docente deve assumir seu papel com profissionalismo, semelhante a qualquer outra profissão, assim como deve ter interesse pela área da docência, servindo como facilitador, orientador e incentivador da aprendizagem.

Em relação à percepção dos respondentes sobre "o que é ser Professor/ Enfermeiro" (questão 12 do questionário), o objetivo dos pesquisadores foi identificar a percepção dos docentes acerca da relação entre a docência e a enfermagem, relação essa que foi indicada, na construção da questão, pela barra entre os termos Professor e Enfermeiro. A análise das respostas a essa questão foi realizada visando à emergência de temas e subtemas que foram agrupados em:

\section{Tema 1: "Conhecimento".}

O primeiro tema define, na percepção dos docentes, a atuação do Professor/ Enfermeiro na relação com o conhecimento, seja pela transmissão, seja por se colocarem como mediadores na construção do conhecimento, seja por entenderem 
que a construção do conhecimento pode propiciar uma transformação. Esse tema tem como referência o olhar desse docente sobre e para o aluno, uma vez que as respostas dizem dessa relação e, a partir dela, explicam e definem "conhecimento".

As respostas apresentadas na sequência indicam a ideia de ensino como reprodução, voltado a "passar um conteúdo" e a transmitir um conhecido recebido anteriormente.

[...] Ser Professor é transmitir conhecimento, interagindo com sujeito/aluno. $\left[\mathrm{DQ} 1^{2}\right]$.

\section{[...] Conhecimento. [DQ6].}

Saviani (1997a; 1997b) nos mostra que, na educação, a chamada pedagogia tradicional se refere ao professor como um transmissor de conteúdo e aos alunos como aqueles que absorvem o que Ihes foi passado. Observa-se, também, que, conforme o descrito por Costa (2009, p. 15), a transmissão tem como atribuição conduzir a inserção dos sujeitos em uma cultura dada, porém sem o exercício da liberdade e da autonomia de transformar essa cultura.

Já as respostas que seguem dizem de um ensino e conhecimento que se apoia na ideia de uma mediação. O Professor/Enfermeiro é tido como um intermediador entre o aluno e o conhecimento.

[...] É ser facilitador do processo ensino-aprendizagem na área de Enfermagem. [DQ2].

[...] Compartilhar conhecimentos. [DQ27].

Segundo Saviani (1997a), o professor pode ser uma ponte para viabilizar a construção do conhecimento pelos alunos. Para Bulgraen (2010), o professor deve atuar de maneira a mediar o conhecimento a fim de despertar no aluno os saberes escolares em interação com o outro, e não apenas receber, passivamente, a informação. Segundo Rodrigues e Mendes Sobrinho (2007), o professor como mediador é um desafiador, pois é necessário buscar conciliar os interesses, os recursos, as técnicas para ministrar as aulas. Ainda, segundo os autores, o Professor/Enfermeiro deve deter conhecimento científico da área, assim como deve interagir com os alunos, facilitando o ensino e a aprendizagem, vivenciando situações do seu cotidiano.

\footnotetext{
${ }^{2}$ Os trechos dos questionários serão identificados por D de Docente, seguido da letra Q relacionado a Questionário, acompanhado da descrição de um número relacionado à ordem dos docentes respondentes dos mesmos.
} 
Já as respostas apresentadas abaixo indicam o ensino e o conhecimento como meio de transformação.

[...] Ser professor, especificamente na área da Saúde, é buscar a arte de ensinar com excelência e dedicação, pensando sempre na formação de profissionais qualificados para o mercado de trabalho, que busquem o bem-estar do ser humano (paciente em si) de forma holística. [DQ18].

[...] É ter a possibilidade de desenvolver uma das qualidades nobres do ser humano que é a partilha. Dividir conhecimento e experiência, focando no ensino/ aprendizagem é uma tarefa difícil na atualidade em que os valores estão individualizados, e por vezes distorcidos. No entanto, é a única maneira de garantirmos um futuro melhor para a humanidade. Indo um pouco mais além, é através do estudo/ensino é que se possibilita transformar o mundo num lugar melhor, menos sofrido e o professor tem papel primordial neste processo. [DQ26].

\section{Tema 2: "Relação Professor/Aluno e formação profissional".}

Neste tema, foram reunidas as colocações dos docentes que, ao responderem "o que é ser Professor/Enfermeiro", disseram da relação com o outro, nesse caso, da relação com o aluno. Essa relação está pautada na troca e no aprendizado do aluno com o professor e essas trocas se dirigem ao conhecimento da Enfermagem. As respostas apresentadas, na sequência, exemplificam essa relação Professor/Aluno:

[...] Modelo, formador de opinião. [DQ3].

[...] É chegar dentro de uma sala de aula e dar o seu melhor e perceber que no final você contribuiu para o processo de aprendizagem, crescimento pessoal e profissional, conhecimento técnico e científico. É perceber que você contribuiu com uma parcela do profissional que ele se tornou. Ser Professor/Enfermeiro é amanhã você se tornar aluno daquela que um dia você ensinou, caminhou junto, ajudou a dar os primeiros passos e conduziu ao primeiro encontro. [DQ13].

[...] Possuir sensibilidade e capacidade técnico-cientifica para incentivar a reflexão de seus clientes/alunos no aprendizado de novos fundamentos conceituais e habilidades atreladas à profissão. [DQ15].

Os professores já se reconhecem como não mais os únicos detentores do saber a ser transmitido, mas como parceiros a quem compete compartilhar seus conhecimentos com outros e mesmo aprender com os outros, inclusive, com seus próprios alunos. É um novo mundo, uma nova atitude, uma nova perspectiva na relação entre o professor e o aluno no Ensino Superior (MASETTO, 2003, p.14). 
[...] Ser enfermeiro é um desafio diário. É um desafio se manter atualizado para preparar a melhor aula, com a melhor estratégia de ensino-aprendizagem que seu aluno pode ter. É um desafio tentar fazer pesquisa e adensar o conhecimento científico de sua área sem apoio financeiro dos órgãos de fomento ou apoio institucional de sua unidade acadêmica. É um desafio conciliar o tempo para fazer extensão e não perder o vínculo com a realidade, para além das práticas propostas no seu plano de ensino e de estágio. É um desafio ainda compor comissões administrativas e tentar tampar os buracos pela falta de funcionários capacitados na administração pública federal. É um desafio você se qualificar, com pouco apoio institucional, se comprometendo financeiramente, psicologicamente, fisicamente e socialmente, de forma a perder o lazer e momentos importantes com a família. É um desafio manter o foco da importância da docência quando você é desrespeitado pelo aluno que acha que não tem que seguir regras e quem tem todos os direitos e quase nada de deveres. É um desafio você ir para o campo de práticas e notar que o enfermeiro do serviço se esqueceu que para ele estar ali, já teve vários professores. Enfim, ser professor é um desafio, uma corrida de obstáculos, é ser um visionário, mesmo sem conseguir muitas vezes enxergar o produto do seu trabalho. [DQ32].

Para Tardif (2000), seu trabalho diário, a prática cotidiana, os saberes, a formação profissional, isso constitui um professor.

Para Rodrigues e Mendes Sobrinho (2007), a formação como processo de reflexão envolve o exame constante das próprias experiências, o diálogo crítico com as teorias pedagógicas e o reconhecimento de que a postura reflexiva deve marcar o trabalho docente, portanto precisa ser explorada no processo de formação do professor, uma vez que favorece a construção da autonomia para identificar e superar as dificuldades do cotidiano.

\section{Tema 3 - "Experiência profissional: Docência e Assistência em Enfermagem".}

Neste terceiro tema, estão as respostas dos docentes que relacionaram o conhecimento a ser ensinado e sua atuação na docência, com a prática da assistência em Enfermagem, dando destaque, nessa relação, à teoria e à prática. Nas respostas dos professores, observa-se uma estreita vinculação entre ensinar e assistir, o que pode ser uma característica da profissão, conforme se apresenta nas respostas a seguir.

[...] Sou apenas professor. O profissional enfermeiro é um eterno educador, cabendo a ele o contínuo educar em saúde, conscientizando o paciente quanto às mudanças de comportamentos e atitudes que visem à sua qualidade de vida. O enfermeiro é também o responsável pela capacitação dos seus auxiliares no aperfeiçoamento da assistência de enfermagem. [DQ4]. 
[...] Oportunidade de contribuir para formação de profissionais da área. Gosto de enfermagem e de ensinar enfermagem. Nunca busquei ser professora, mas na profissão de enfermagem sempre fui professora, ensinando pacientes, família, comunidades, técnicos, auxiliares e enfermeiros. Meu primeiro contato com o ensino foi enquanto acadêmica no Projeto Rondon, onde ministrei um curso de atendente de enfermagem. Daí para frente o ensino permeou minha vida profissional. Trabalhei na assistência também. Logo após formada, fui convidada a ser professora em cursos de auxiliares e técnicos de enfermagem, pela escassez de professor/enfermeiro, o que fiz com muito prazer. E estou como professora de enfermagem na graduação desde a criação do Curso na Universidade da cidade onde resido. Me sinto realizada em participar do processo ensino-aprendizagem. Ser professor é aprender junto. É buscar sempre e estar sempre atualizada. É ser cuidadora e ensinar a cuidar. É ser pesquisadora para contribuir com novos avanços na enfermagem. É ser responsável por promover a saúde duplamente, tendo de assistir na promoção da saúde e ensinar assistir. Nunca buscaria ser professora pelo simples fato de aptidão para ser professora. Mas sendo enfermeira senti necessidade de ser professora para ensinar a profissão e assim me sinto bem e realizada em ser professora de enfermagem, pois participei do processo ensino-aprendizagem e também da assistência. [DQ08].

[...] É contribuir para que mudanças na área da educação e, especificamente da Enfermagem, sejam realizadas para que nossos pacientes sejam melhores assistidos. [DQ19].

Os professores demonstraram uma estreita relação entre sua atuação profissional na Enfermagem e o que ensinam no Ensino Superior.

[...] É ter a oportunidade de atuar na assistência de Enfermagem, por meio de práticas e estágios, e poder trabalhar no ensino e na produção de conhecimento. [DQ07].

[...] Possibilita desenvolver o processo ensino-aprendizagem articulando teoria e prática, problematizando as situações encontradas nas práxis, estimulando o exercício da reflexão-ação, da reflexão da reflexão-ação. [DQ09].

[...] Ser enfermeiro é viver no limite do conhecimento e da execução ao processo saúde-doença. Ser professor é aplicar o conhecimento teórico e prático, experiências vividas para melhor entendimento do acadêmico. [DQ14].

[...] Ser professor/enfermeira para mim é muito importante porque ensino a profissão que já exerci. E isso, é... já foi comentado pelos alunos. [DQ28].

Tardif e Lessard (2011) afirmam que repensar a formação dos professores é levar em conta os saberes dos professores e as realidades específicas do trabalho 
cotidiano, reconhecendo o professor como um profissional produtor de saberes. Entende o saber docente como aquele formado pela associação, mais ou menos coerente, de saberes oriundos da formação profissional, transmitido pelas instituições de formação de professores; disciplinares, que correspondem aos diversos campos do conhecimento; curriculares, das instituições escolares, compreendem os discursos, objetivos, conteúdos e métodos que os professores devem aprender a aplicar; e os experienciais, baseados no seu trabalho cotidiano, brotam da experiência e são por ele validados. Ainda considera os saberes experienciais como núcleo vital do saber docente.

Nos itens abaixo, os docentes abordam, pela descrição dos professores/ enfermeiros, a sua realização na profissão, seja ela docente ou assistencial.

[...] Pra mim, é uma boa oportunidade profissional, considerando as opções de jornada de trabalho e remuneração da categoria no mercado. [DQ10].

[...] Minha realização profissional. [DQ30].

[...] Realização pessoal e atualização constante em decorrência dos desafios do dia a dia. [DQ40].

A formação do docente enfermeiro precisa ser redirecionada de forma que esteja baseada na reflexão sobre a prática cotidiana, considerando o professor como um pesquisador da própria prática. É de fundamental importância o estabelecimento de programas de formação continuada voltados para a docência, que considerem a reflexão sobre a prática, a universidade como o lócus de formação, o coletivo e o saber experiencial (RODRIGUES; MENDES SOBRINHO, 2007).

Para Nóvoa (1999), a formação pode estimular o desenvolvimento profissional dos professores no quadro de uma autonomia contextualizada da profissão docente. O autor ainda afirma que a valorização dos paradigmas de formação é importante para promover o preparo de professores reflexivos, assumindo, assim, a responsabilidade do seu próprio desenvolvimento profissional, e que participem como protagonistas na implementação das políticas educativas.

\section{CONSIDERAÇÕES FINAIS}

Esta pesquisa propôs investigar a formação pessoal e pedagógica do professor que assume a docência, neste caso, em Enfermagem, em instituições de Ensino Superior. Objetiva também conhecer como se buscam qualificações profissionais 
(específicas e pedagógicas) e se é possível estabelecer uma relação entre essa formação e a atuação docente.

Foi enviado um questionário para enfermeiros docentes de instituições de Ensino Superior da região do Sul de Minas Gerais, sendo totalizados 41 enfermeiros docentes respondentes. Predominantemente, é uma profissão do sexo feminino; entretanto, nas últimas décadas, o número de homens que ingressaram na profissão de enfermagem vem aumentando. Outro ponto é a faixa etária, que sofre variação entre os pesquisados. Na formação profissional, predominantemente, destacaram-se aqueles com titulação de doutores e mestres, chegando a quase $80 \%$ dos participantes desta investigação, sugerindo que os enfermeiros docentes estão em constante busca por aprimoramento profissional.

Dos sujeitos pesquisados que entram para a docência, é praticamente simultânea a atuação na assistência e como professor. Outro ponto a ser destacado é a formação complementar na área pedagógica, pois a consideram importante para a atuação como docente. Destaca-se também a experiência profissional, sendo esta um importante instrumento para docência em Enfermagem. É importante que a prática pedagógica do enfermeiro docente passe por um processo contínuo de reflexão e (re)facção já que essa postura promove uma prática capaz de modificar o contexto educacional do ensino de Enfermagem.

O questionário foi confeccionado pelos autores da pesquisa e contou com questões discursivas, sendo o foco o enfermeiro docente no Ensino Superior. Nessa perspectiva, observa-se que o respondente identifica a docência como um mediador e transformador. Além disso, salienta a importância da formação crítico-reflexiva como poder de construção do ensino-aprendizagem.

Nesse mesmo item, um dos pontos em destaque são os docentes que relacionam o conhecimento a ser ensinado e sua atuação na docência com a prática da assistência em Enfermagem, dando destaque, nessa relação, à teoria e à prática. Nas respostas dos professores, observa-se uma estreita vinculação entre ensinar e assistir, o que pode ser uma característica da profissão. Na pesquisa Enfermeiro docente, pode-se observar que os professores demonstraram uma estreita relação entre sua atuação profissional na Enfermagem e o que transmitem no Ensino Superior.

Por fim, esta pesquisa vem provar, através dos dados coletados, a importância em se acreditar no processo de transformação do ensino de enfermagem. A formação do docente precisa ser redirecionada a fim de que esteja baseada na reflexão sobre a prática cotidiana, considerando o professor como um pesquisador da própria 
prática, tendo como foco o docente, que é portador de saberes e experiências que podem ser construídos e ressignificados a cada dia, de forma que sua prática seja o reflexo dessa constante formação.

\section{REFERÊNCIAS}

BEHRENS, M. A. A formação pedagógica e os desafios do mundo moderno. In: MASETTO, M. (Org.). Docência na universidade. 11. ed. Campinas, SP: Papirus, 2012. p. 61-74.

BULGRAEN, V. C. O papel do professor e sua mediação nos processos de elaboração do conhecimento. Revista Conteúdo, Capivari, SP, v. 1, n. 4, p. 30-8 ago./dez. 2010.

CICILLINI, G. A. Professores universitários e sua formação: concepções de docência e prática pedagógica. In: NOVAIS, G. S.; CICILLINI, G. A. (Org.). Formação docente e práticas pedagógicas: olhares que se entrelaçam. Araraquara, SP: Junqueira\&Marin; Belo Horizonte: FAPEMIG, 2010. p. 19-43.

COSTA, S. G. Considerações sobre educação e transmissão simbólica. 2009. 115p. Dissertação (Mestrado em Psicanálise, Saúde e Sociedade) - Universidade Veiga de Almeida, Rio de Janeiro, 2009.

JUNGES, K. dos S.; BEHRENS, M. A. Prática docente no ensino superior: a formação pedagógica como mobilizadora de mudança. Perspectiva, Florianópolis, SC, v. 33, n. 1, p. 285-317, jan./abr. 2015.

MASETTO, M. T. Professor universitário: um profissional da educação na atividade docente. In: MASETTO, M. (Org.). Docência na universidade. 11. ed. Campinas, SP: Papirus, 2012. p. 9-27. . Competência pedagógica do professor universitário. São Paulo: Summus, 2003.

NÓVOA, A. (Org.). Profissão professor. 2. ed. Porto: Editora Porto, 1999.

RODRIGUES, M. T. P.; MENDES SOBRINHO, J. A. de C. Enfermeiro professor: um diálogo com a formação pedagógica. Revista Brasileira de Enfermagem, Brasília, v. 60, n. 4, p. 456-9, jul./ ago. 2007.

SAVIANI, D. Escola e democracia: polêmicas do nosso tempo. 31. ed. Campinas, SP: Autores Associados, 1997a.

. Pedagogia histórico-crítica: primeiras aproximações. 6. ed. Campinas, SP: Autores Associados, 1997b.

SOUZA, D. M. de. Preparo do enfermeiro para a docência na educação profissional técnica de nível médio sob a ótica de Lee Shulman. 2013. Tese (Mestrado em Enfermagem) Universidade Federal de Santa Catarina (UFSC), Florianópolis, SC, 2013.

TARDIF, M. Saberes profissionais dos professores e conhecimentos universitários. Revista Brasileira de Educação, n. 13, p. 5-24, jan./abr. 2000. 
TARDIF, M.; LESSARD, C. O trabalho docente: elementos para uma teoria da docência como profissão de interações humanas. 6. ed. Petrópolis, RJ: Vozes, 2011.

\section{Sobre os autores:}

João Paulo Soares Fonseca: Mestre em Educação pela Universidade Vale do Sapucaí (UNIVÁS). Bacharel em Enfermagem e complementação Pedagógica em Ciências Biológicas pela Universidade Vale do Rio Verde. É Enfermeiro do Serviço de Atendimento Móvel de Urgência e Emergência (CISSUL/SAMU) USA 01 - Base Varginha, Enfermeiro do Núcleo de Educação Permanente CISSUL/SAMU - Varginha e Enfermeiro da 2a Companhia Aérea do Bombeiro Militar de Minas Gerais, serviço Aéro Médico CISSUL/SAMU, Varginha, MG. E-mail: sop.fad@gmail.com

Carla Helena Fernandes: Graduação em Pedagogia pela Universidade Federal de Mato Grosso do Sul (UFMS), especialização em Psicopedagogia, Mestrado em Educação pela Universidade Católica Dom Bosco (UCDB) e Doutorado em Educação pelo Programa de Pós-Graduação da Faculdade de Educação da UNICAMP. É professora do Mestrado em Educação da Universidade do Vale do Sapucaí (UNIVÁS), em Pouso Alegre, MG. Como pesquisadora participa dos seguintes grupos de estudo e pesquisa: Grupo de Pesquisa em Educação e Gestão (GPEG/UNIVÁS), Grupo de Estudos e Pesquisas em Educação Continuada (GEPEC), da Faculdade de Educação da UNICAMP, e do Grupo de Estudos Escola, Formação e Alteridade (GREEFA), do Departamento de Educação da UNESP - Rio Claro, onde realiza Estágio Pós-Doutoral.

E-mail: carlahelenafernandes@yahoo.com.br

\section{Recebido em dezembro de 2016.}

\section{Aprovado para publicação em maio de 2017.}

